\title{
Derrotabilidade das Regras e Técnicas de Decisões da Jurisdição Constitucional
}

\author{
Defeasibility of legal rules and decision techniques of \\ constitutional jurisdiction
}

Mauricio Martins Reis ${ }^{1}$

Alexandre Prevedello ${ }^{2}$

\begin{abstract}
RESUMO
O ensaio investiga a noção de derrotabilidade das regras jurídicas (a possibilidade de uma regra jurídica válida ser excepcionada no momento de sua aplicação) e a correlaciona com as técnicas de decisões da jurisdição constitucional (interpretação conforme a constituição, inconstitucionalidade parcial sem redução de texto e decisões constitucionais manipulativas). Para tanto, adotaram-se os métodos dedutivo de abordagem, monográfico de procedimento e sistemático de interpretação, mediante tipo de pesquisa teórico e técnica de pesquisa bibliográfica. Conceituam-se e diferenciam-se tais categorias jurídicas para, ao final, analisar a atuação do Supremo Tribunal Federal no caso do aborto de feto anencéfalo - ADPF 54. Conclui-se que tal caso exemplifica a utilização distorcida pelo Supremo Tribunal Federal da técnica da interpretação conforme a constituição, pois houve a redução da finalidade de uma regra jurídica, hipótese que corresponde ao fenômeno da derrotabilidade das regras jurídicas e, desse modo, à inconstitucionalidade parcial sem redução de texto.
\end{abstract}

\section{PALAVRAS-CHAVE:}

Derrotabilidade. Interpretação conforme. Decisões manipulativas.

\begin{abstract}
This essay investigates the defeasibility of legal rules (the possibility of making an exception to a valid legal rule at the time of its application) and associates it to the decision techniques of constitutional jurisdiction (interpretation according to the constitution, unconstitutional partial sentence without loss of text and manipulative constitutional sentences). The theoretical research was undertaken by means of a deductive approach, a monographic treatment of the

\footnotetext{
${ }^{1}$ Doutor em Direito Público pela Universidade do Vale do Rio dos Sinos (UNISINOS), Doutor em Filosofia pela PUCRS, Mestre em Direito pela UNISINOS, Especialista em Jurisdição Constitucional e Direitos Fundamentais (Universidade de Pisa, Itália), Professor da graduação e Mestrado em Direito na Fundação Escola Superior do Ministério Público (FMP-RS). E-mail: mauriciomreis@terra.com.br.

${ }^{2}$ Mestre em Direito pela Fundação Escola Superior do Ministério Público (FMP-RS), assessor de Desembargador no Tribunal de Justiça do Estado do Rio Grande do Sul. Professor convidado de direito constitucional no Curso Preparatório Prova da OAB da Fundação Escola Superior do Ministério Público do Rio Grande do Sul. E-mail: aleprevedello@hotmail.com
} 
subject and a systematic interpretation of the findings of a bibliographical review. These legal categories are conceptualized and differentiated, and then the Brazilian Supremo Tribunal Federal proceeding in the anencephalic abortion case - ADPF 54 (Claim of non-compliance with the fundamental precept 54) is analyzed. It is concluded that such a case exemplifies the distorted use by the Brazilian Supremo Tribunal Federal of the interpretation according to the constitution technique, since there was a reduction in the purpose of a legal rule, a hypothesis that corresponds to the phenomenon of the defeasibility of legal rules and, thus, to the unconstitutionality partial sentence without loss of text.

\section{KEYWORDS:}

Defeasibility. Interpretation according to the Constitution. Manipulative sentences.

\section{INTRODUÇÃO}

A formulação de padrões de conduta por meio da positivação de regras gerais é indispensável para regular de modo harmônico a vida em sociedade e constitui objeto relevante da teoria do direito. Trata-se de atividade ou função predominantemente legislativa que se ocupa, portanto, de atribuir consequências jurídicas ou soluções razoáveis para fatos relevantes, sendo notória sua dificuldade, sobretudo porque o objetivo é que o regramento abranja a universalidade dos conflitos.

A atividade judicial, por sua vez, tem como objetivo aplicar tais regras gerais aos casos concretos de modo mais consentâneo e igualitário possível, função que tem se mostrado cada vez mais complexa, notadamente pela utilização de princípios jurídicos e, ainda, de conceitos jurídicos indeterminados e cláusulas abertas.

Essa problemática acentua-se quando do exercício da jurisdição constitucional, especialmente a partir da segunda metade do século vinte com a institucionalização de direitos fundamentais nas Constituições da maioria dos países do mundo ocidental e com o 
estabelecimento de Tribunais Constitucionais que arrecadaram a competência de preservar tais direitos ante os possíveis ataques da maioria parlamentar (função contramajoritária) ${ }^{3}$.

Discute-se, assim, a legitimação democrática dos Tribunais Constitucionais, ou dos limites da jurisdição constitucional no âmbito do Estado Democrático de Direito. E é exatamente nesse difícil contexto que se insere o fenômeno da derrotabilidade das regras jurídicas, na medida em que ele remete à ideia de exceções no direito aplicado, as quais resultam evidenciadas no processo de concretização do direito posto e invariavelmente confrontadas pela jurisdição no diuturno trato das relações sociais com tessitura viva.

Não é difícil perceber que isso representa em tese um significativo risco à segurança jurídica, assim como pode gerar um protagonismo excessivo e potencialmente arbitrário do judiciário, desequilibrando a convivência harmônica dos poderes, que se constitui como um dos pilares da democracia. Em outros termos, o judiciário é um intérprete privilegiado, mas que não pode comprometer os alicerces referenciais do sistema democrático. Nesse contexto, o objetivo desse artigo é analisar o fenômeno da derrotabilidade das regras jurídicas por ocasião das técnicas de decisão no controle de constitucionalidade, para fins de melhor compreensão desse importante e eloquente fenômeno jurídico, problematizando-as topicamente no denominado caso do aborto do feto anencéfalo (ADPF 54) - considerado pelos próprios membros do Supremo Tribunal Federal com um caso histórico, ante a sua relevância e dificuldade jurídica.O desenvolvimento do trabalho ocorrerá em cinco etapas. Primeiro, faz-se um breve exame da derrotabilidade das regras, com a adoção de um conceito que será utilizado na parte final do ensaio. Depois, são analisadas as técnicas de decisões da jurisdição constitucional (interpretação conforme a Constituição, inconstitucionalidade parcial sem redução de texto e decisões de cunho manipulativo). Serão conceituadas e diferenciadas essas categorias jurídicas para, ao final, analisar-se a atuação do Supremo Tribunal Federal no caso do aborto do feto

\footnotetext{
${ }^{3} \mathrm{O}$ caso LÜTH-URTEIL (BVERFGE 7, p. 198-230), julgado pelo Tribunal Constitucional Alemão em 15/01/1958, é considerado o marco paradigmático acerca do reconhecimento da força normativa dos direitos fundamentais e também do papel da jurisdição constitucional (para muitos é a decisão mais importante da história do constitucionalismo alemão pós-guerra). No julgamento, o Tribunal afirmou que os direitos fundamentais instituem uma ordem objetiva de valores e aplicam-se mediante a técnica de ponderação a partir das particularidades do caso concreto, reconhecendo, ainda, que sua eficácia jurídica também incide nas relações privadas ou entre particulares (eficácia horizontal dos direitos fundamentais), além de explicitar o significado do direito fundamental à livre expressão do pensamento no Estado Democrático de Direito.
} 
anencéfalo - trazido à Corte por meio da ADPF 54 - e, na medida do possível, concluir por aquela técnica que melhor se coadunaria com o fenômeno da derrotabilidade.

\section{DERROTABILIDADE DAS REGRAS JURÍDICAS}

O termo derrotabilidade (defeasibility) relaciona-se com a ideia de exceções e, desse modo, é objeto de estudos da teoria do direito e da argumentação jurídica, quer dizer, por intermédio dele se investiga o papel das exceções no raciocínio jurídico (ponto de vista da lógica jurídica), no estudo das lacunas e das indeterminações do direito (ponto de vista da interpretação jurídica) e na justificativa das premissas fáticas e normativas que amparam uma decisão eminentemente contra legem (ponto de vista da decisão judicial).

Isso significa que a derrotabilidade remete a temas importantes os quais, embora conectados, não se confundem, impondo-se um tratamento sistemático e adequadamente rigoroso acerca dos seus diferentes significados ${ }^{4}$. No Brasil - onde o tema tem adquirido notoriedade apenas nos últimos anos -, tal depuração ainda não ocorre, motivo pelo qual há referências indistintas a derrotabilidade ou superabilidade ${ }^{5}$ (a) das normas, característica comum aos princípios e às regras para alguns ou exclusiva das regras jurídicas para outros, (b) do raciocínio jurídico, (c) dos conceitos jurídicos.

Herbert L. A. Hart, ao reconhecer primeiramente o caráter derrotável dos conceitos jurídicos no ensaio The Ascription of Responsibility and Rights (1949, p. 171-194) e em um segundo momento, no capítulo VII - Formalismo e ceticismo sobre as regras - do livro o Conceito de Direito (2001, p. 139-168), o caráter derrotável das regras jurídicas, é

\footnotetext{
${ }^{4}$ Beltran e Ratti (2012a, p. 01) referem que a defeasibility, além da ciência jurídica, é objeto de estudo de outras áreas do conhecimento, como a lógica, a epistemologia e a filosofia, circunstância que acarreta confusões conceituais. Nesse mesmo contexto, Rodríguez e Sucar (2003, p. 103-155) catalogaram onze circunstâncias ou sentidos ordinariamente referidos como causadores da derrotabilidad no direito.

${ }^{5} \mathrm{O}$ termo tem sido traduzido para o português ora como derrotabilidade ora como superabilidade, como destacam Gavião Filho e Munhoz de Andrade (2015, p. 178).
} 
uniformemente citado ${ }^{6}$ como o idealizador da teoria ou do conceito de derrotabilidade das regras jurídicas ${ }^{7}$.

Ainda que o objetivo não seja examinar a obra de Hart, cabe o registro de que a introdução do termo defeasible no âmbito do direito ocorreu naquele ensaio inaugural (1949, p. 174-175) para se referir ao fato de que os conceitos jurídicos (o contrato, por exemplo) caracterizam-se pelo uso da palavra unless (a menos que), ou seja, eles não podem carregar condições absolutamente necessárias e suficientes para fins de aplicação em todo e qualquer caso futuro, na medida em que sempre haverá uma lista de exceções ou de exemplos contrários que não podem ser especificados antecipadamente.

E o aprimoramento da teoria ocorreu na clássica obra "O Conceito de Direito", quando Hart discorreu sobre o problema da textura aberta do direito, que não concerne somente a questões relacionadas à linguagem e à interpretação jurídica, mas sim ao problema da acomodação das regras gerais aos casos concretos, no sentido de que uma regra pode ser excepcionada e ainda assim ter preservada a sua força abstrata original, ou seja, remanescendo como uma regra geral válida para situações típicas com o resguardo de sua força normativa.

Duarte d'Almeida (2015, p. 03-05) afirma que isso significa que o Direito admite exceções em casos irregulares - de características excepcionais -, o que torna injusto decidir estritamente conforme a regra aplicável em sua prognose exegética ortodoxa. Tal "perspectiva persistente" é um dilema para o parlamento, que não consegue - nem o poderia - antecipar todas as exceções relevantes supervenientes à formulação do critério legislativo. Do mesmo modo, a linha entre o que faz parte da exceção e o que faz parte da regra (elementos ordinários da regra) é mais difícil de ilustrar do que se imagina e foi exatamente essa controvérsia suscitada por Hart, a qual pode ser considerada como o dilema contemporâneo do judiciário.

Assim, o regramento das exceções no Direito ocorre em dois momentos distintos com repercussões e dificuldades também diferenciadas. O primeiro momento é o de sua institucionalização via parlamento (legislative moment), o qual não é aconselhável, na medida em que a exceção, posta em caráter preliminar, limitaria o alcance da regra. O segundo

\footnotetext{
${ }^{6}$ Nesse sentido se manifestam Bäcker (2011, p. 61), Pino (2010, p. 09) e Vasconcellos (2010, p. 53-54).

${ }^{7}$ O ensaio de 1949, embora tenha sido rejeitado pelo próprio Hart, conforme MacCormick ((2010, p. 30), teve algumas de suas ideias mantidas e aperfeiçoadas quando da elaboração da doutrina da textura aberta do direito, consoante esclarece Graeff (2015).
} 
momento, o da introdução no processo judicial, isto é, quando da aplicação da regra, de uma cláusula de exceção (adjudicative moment), representa o ponto problemático e interessante a ser investigado (ATRIA, 2002, p. 124).

No tocante ao fundamento e à definição da exceção e sua relação curiosa e paradoxal no Direito, bem como sobre o papel do judiciário na manutenção e recomposição da coerência do ordenamento, destaca-se o pensamento de Grau (2014, p. 321-325):

\begin{abstract}
A exceção é o caso que não cabe no âmbito da normalidade abrangido pela norma geral - a norma geral deixaria de ser geral se a contemplasse. Da exceção não se encontra alusão no discurso da ordem jurídica vigente; define-se como tal justamente por não ter sido descrita nos textos escritos que compõem essa ordem. É como se nesses textos de direito positivo não existissem palavras que tornassem viável sua descrição. Por isso dizemos que a exceção está no direito, ainda que não se a encontre nos textos normativos de direito positivo. [...] À afirmação de que a exceção é o caso que não cabe no âmbito da normalidade abrangido pela norma geral corresponde outra: a de que as normas só valem para as situações normais; (...). A exceção não está situada além do ordenamento, senão no seu interior. Pois o estado de exceção é uma zona de indiferença entre o caos e o estado da normalidade; zona de indiferença, no entanto, capturada pelo direito. [...]. A situação de exceção, embora não prevista pelo direito positivo (=pelas normas), há de ser decidida em coerência com a ordem concreta da qual a Constituição é a representação mais elevada no plano do direito posto. Esta ordem concreta é anterior ao direito posto pelo Estado. Arranca de um direito pressuposto e expressa a visibilidade de um nomos. O processo de objetivação que dá lugar ao fenômeno jurídico não tem início na emanação de uma regra, mas sim em um momento anterior, no qual aquela ordem é culturalmente forjada. Refiro-me a uma ordem concreta, situada geograficamente e no tempo, com as marcas históricas e culturais que conformam tal como ela é. Por isso mesmo, incompleta e contraditória, reclamando permanentemente complementação, refazimento e superação de situações de exceção. Ao judiciário, sempre que necessário, incumbe decidir regulando também essas situações de exceção. Mas ao fazê-lo não se afasta do ordenamento. Aplica a norma à exceção desaplicando-a, isto é, retirando-a da exceção, retirando-se desta. [...]. Ao interpretar/aplicar o direito - porque aí não há dois momentos distintos, mas uma só operação [v. Grau 2009 e 2007] -, ao praticar essa única operação, isto é, ao interpretar/aplicar o direito, o Judiciário não se exercita no mundo das abstrações, porém trabalha com a materialidade mais substancial da realidade. Decide não sobre teses, teorias ou doutrinas, mas a respeito de situações do mundo da vida. Não cumpre seu ofício visando a prestar contas a Montesquieu ou a Kelsen, porém para vivificar o ordenamento, todo ele. Por isso o toma na sua totalidade. Não procede como mero leitor de seus textos - para o quê bastaria a alfabetização -, mas produzindo normas, tecendo e recompondo o próprio ordenamento. [...]. A exceção está dentro do direito posto pelo Estado, porém concomitantemente destrói esse mesmo direito - o que não surpreende aos que acreditam na dialética materialista. A exceção está dentro do direito, mas nos transporta para fora dele... O estado de exceção é uma zona de indiferença entre o caos e o estado da normalidade, zona de indiferença, não obstante, capturada pelo direito.
\end{abstract}

Nesse aspecto, é de se sublinhar a noção de equidade (notion of Equity) como uma subcategoria central da derrotabilidade do raciocínio jurídico e que pode ser denominada de derrotabilidade equitativa (equitable defeasibility), a qual é conhecida desde os escritos de Platão e Aristóteles na antiguidade grega: ela estampa a acomodação de exceções às regras 
gerais quando a sua aplicação em casos particulares seja geradora de injustiças extremas ou de absurdos, mas a regra permanece válida para ser aplicada nos demais casos (BIX, 2012, p. 198).

Para Atria (2002, p. 123), as regras atribuem consequências normativas para fatos relevantes, mas ao mesmo tempo possuem uma característica intrigante: elas não são dotadas de um bom comportamento, quer dizer, em alguns casos, quando confrontadas com outros fatos também relevantes, os seus resultados jurídicos não são justos. E isso acarreta outra característica peculiar e exclusiva: as regras jurídicas são derrotáveis.

Com efeito, em um sistema normativo dividido em regras e princípios, a derrotabilidade é uma característica específica das regras jurídicas, pois, ao ser definida no sentido da admissão de uma cláusula de exceção, "então deve-se necessariamente presumir que essa norma tenha a estrutura de uma regra que permita a subsunção de certos fatos ou condutas em sua hipótese de incidência" (BUSTAMANTE, 2010), circunstância que não ocorre nos princípios em que o exame de todas as circunstâncias dos casos futuros é inerente ao conceito de otimização e da própria técnica de ponderação (BÄCKER, 2011, p. 68) ${ }^{8}$.

Segue então que uma regra derrotável não é aquela não aplicável ao caso; uma regra somente é derrotada se ela não for aplicada quando era o caso de ser aplicada. Em outra formulação: uma regra é derrotável se existem - ou podem existir - casos abrangidos pelo significado da regra em que ela não se aplica (ATRIA, 2002, p. 124)

Portanto, a partir dessa breve explicação, a derrotabilidade das regras pode ser entendida como a capacidade destas em acomodarem exceções implícitas que devem ser ocasionalmente reconhecidas pelo judiciário.

\section{INTERPRETAÇÃO CONFORME A CONSTITUIÇÃO}

\footnotetext{
${ }^{8}$ Backer (2011) inclusive advoga que a derrotabilidade (no sentido da admissão de uma cláusula de exceção) é o critério definitivo para distinguir regras de princípios.
} 
A interpretação conforme a Constituição examinada aqui não é um princípio de interpretação constitucional nem um fenômeno jurídico similar à derrotabilidade, mas sim uma técnica de decisão no controle de constitucionalidade; no entanto, não deixa de ser também uma regra de interpretação da legislação infraconstitucional ${ }^{9}$ cujo parâmetro, evidentemente, é a Constituição da República, o que também significa que "não há como escapar de um mínimo de interpretação da própria constituição" (SILVA, 2006, p. 192).

A forma como ordinariamente é tratada pela doutrina à luz de sua fonte, o direito alemão ${ }^{10}$, restringe o seu objeto, na medida em que definido no sentido de que "no caso de polissemia de sentidos de um acto normativo, a norma não deve considerar-se inconstitucional enquanto puder ser interpretada de acordo com a constituição" (CANOTILHO, 2003, p. 958) ${ }^{11}$, ou, em outros termos, "quando há mais de uma interpretação possível para um dispositivo legal, deve ser dada preferência àquela que seja conforme a constituição" (SILVA, 2006, p. 192).

É, portanto, uma técnica - reconhecida no parágrafo único do art. 28 da Lei 9.868/1999 - para salvar o ato normativo infraconstitucional como um todo da declaração de inconstitucionalidade ${ }^{12}$, desde que seja possível compatibilizar texto e interpretação, ou seja, devem ser observados os limites semânticos do texto ${ }^{13}$ ou a moldura que é fornecida pelo legislador por intermédio do texto ${ }^{14}$, quer dizer, sua utilização encontra limites objetivos:

(i) a interpretação conforme a constituição só é legítima quando existe um espaço de decisão (= espaço de interpretação) aberto a várias propostas interpretativas, umas em conformidade com a constituição e que devem ser preferidas, e outras em desconformidade com ela; (ii) no caso de se chegar a um resultado interpretativo de uma norma jurídica em inequívoca contradição com a lei constitucional, impõe-se a rejeição, por inconstitucionalidade, dessa norma (= competência de rejeição ou não

\footnotetext{
${ }^{9}$ Conforme Virgílio Afonso da Silva (2006, p. 191-192), “quando se fala em interpretação conforme a constituição, não se está falando de interpretação constitucional, pois não é a constituição que deve ser interpretada em conformidade com ela mesma, mas as leis infraconstitucionais".

${ }^{10}$ Conforme DIMOULIS; LUNARDI, 2014, p. 405.

${ }^{11} \mathrm{O}$ constitucionalista português complementa (2003, p. 958-959) no sentido de que "a interpretação de leis em conformidade com a Constituição é um meio de o TC (e os outros tribunais) neutralizarem violações constitucionais, escolhendo a alternativa interpretativa conducente a um juízo de compatibilidade do acto normativo com a Constituição".

12 Nesse mesmo sentido Leo Brust (2009, p. 508), afirma que "na interpretação conforme a Constituição 'propriamente dita' o julgador escolhe entre interpretações alternativas existentes no conteúdo normativo do preceito legal e preserva o seu texto".

${ }^{13}$ Acerca dos limites propostos pela jurisprudência do Supremo Tribunal Federal para tal instituto, consulte-se MENDES, 2010, p. 1430.

14 "Quando a letra não permite certa interpretação e se ela for considerada a única que conciliaria a norma com a Constituição, deve ser declarada a inconstitucionalidade da norma (ou a omissão inconstitucional). Temos aqui o limite textual imposto à interpretação conforme" (DIMOULIS; LUNARDI, 2014, p. 415).
} 
aplicação de normas inconstitucionais pelos juízes), proibindo-se a sua correção pelos tribunais (= proibição de correcção de norma jurídica em contradição inequívoca com a constituição); (iii) a interpretação das leis em conformidade com a constituição deve afastar-se quando, em lugar do resultado querido pelo legislador, se obtém uma regulação nova e distinta, em contradição com o sentido literal ou sentido objectivo claramente recognoscível da lei ou em manifesta dessintonia com os objectivos pretendidos pelo legislador (CANOTILHO, 2003, p. 1.227) ${ }^{15}$.

Nesse contexto, quando uma regra admite duas ou mais interpretações, é imprescindível a definição pelos Tribunais daquela que melhor se compatibilize com a Constituição para fins de coerência do ordenamento jurídico.

Contudo, isso não significa que a técnica encontre fundamento na necessidade de unidade da ordem jurídica, pois a Constituição ser definida enquanto parâmetro interpretativo é diferente de dar preferência à interpretação que mantém a lei no ordenamento, até porque o reconhecimento da inconstitucionalidade também garante a unidade do ordenamento jurídico ${ }^{16}$; a Constituição como parâmetro de interpretação é fundamento do controle de constitucionalidade em geral (SILVA, 2006, p. 195).

Afirma-se, ainda, que a interpretação conforme é uma exigência que decorre da presunção relativa de constitucionalidade $^{17}$ da legislação infraconstitucional ${ }^{18}$, que possui amparo normativo nos próprios ditames da democracia e da separação de poderes ${ }^{19}$.

Questiona-se o valor argumentativo dessa correlação, seja por ser demasiadamente simplista (nem sempre se terá apenas a variável de duas interpretações possíveis, uma

\footnotetext{
${ }^{15}$ Embora esses limites sejam ordinariamente referidos pela doutrina, não há consenso sobre o tema. Uma crítica a essas fronteiras da interpretação conforme, com fundamento na hermenêutica jurídica, encontra-se em STRECK, 2002, p. 451-461.

${ }^{16}$ Do mesmo modo posiciona-se Brust (2009, p. 508).

${ }^{17}$ Como marco à interpretação conforme a constituição, no âmbito da jurisprudência do Supremo Tribunal Federal, Silva (2006, p. 192) cita a seguinte passagem do voto proferido pelo Min. Moreira Alves no Rep. 1417, de 1987: "A interpretação da norma sujeita a controle deve partir de uma hipótese de trabalho, a chamada presunção de constitucionalidade, da qual se extrai que, entre dois entendimentos possíveis do preceito impugnado, deve prevalecer o que seja conforme à Constituição".

${ }^{18}$ Interessante registrar que a presunção de constitucionalidade das leis foi formulada originalmente por James B. Thayer, jurista norte-americano que, em artigo publicado em 1893 na Harvard Law Review, o qual sustentava a necessidade de autocontenção judicial no controle de constitucionalidade (SARMENTO; SOUZA NETO, 2013, p. 145). Há uma constante evolução doutrinária sobre o tema a ponto de se defender uma presunção graduada de constitucionalidade dos atos normativos. O tema é objeto de ensaios de Cleve e Lorenzetto (2015, p. 17-73) e de Sarmento e Souza Neto (2013, p. 119-161), que buscam adaptar às particularidades do sistema jurídico pátrio tais níveis de intensidade ou de parâmetros diferenciados no exame da constitucionalidade.

19 “Os principais fundamentos teóricos para a presunção relativa de constitucionalidade das leis são a democracia e a separação de poderes. Dita presunção expressa a deferência devida aos atos emanados dos órgãos eleitos pelo povo. O princípio impõe que se respeite a esfera de atuação própria de cada poder do Estado, o que envolve a preservação do espaço das escolhas normativas feitas pelo Poder Legislativo.” (SARMENTO; SOUZA NETO, 2013, p. 145).
} 
constitucional e outra não), seja porque a deferência que se deve atribuir à decisão do legislador (sobretudo em casos difíceis) é somente uma parte das inúmeras variáveis que a complexidade de determinadas causas pode envolver (SILVA, 2006, p. 195-196).

Ante tal conjuntura, Silva (2006, p. 204) conclui que a função dos critérios interpretativos é a de assinalar uma direção ou um caminho, o que não ocorre com a técnica da interpretação conforme, pois "aponta para uma direção completamente equivocada, que se baseia no dever de tentar salvar toda e qualquer lei que, ainda que minimamente, possua alguma fagulha de constitucionalidade", razão pela qual a sua única função é a de legitimar a centralização da tarefa de interpretação da Constituição e das leis em um único órgão, o Supremo Tribunal Federal ${ }^{20}$.

Em sentido diverso, Dimoulis e Lunardi (2014, p. 406) asseveram que a justificação mais convincente da técnica consiste na necessidade de o judiciário ser prudente quando do exame da constitucionalidade das leis para não invadir o espaço do legislador.

A partir disso se verifica que interpretação conforme possui dificuldades dogmáticas cujo enfrentamento não vem encontrando razoável atuação por conta do Supremo Tribunal Federal, visto que normalmente a Corte brasileira a contempla para hipóteses absolutamente diversas daquelas indicadas pela doutrina, quer dizer, o Supremo faz uso desse expediente quando não há duas ou mais interpretações possíveis para o texto ou quando é o caso de declaração de nulidade parcial sem redução de texto, circunstância problematizada no próximo tópico.

\section{INCONSTITUCIONALIDADE PARCIAL SEM REDUÇÃO DE TEXTO}

\footnotetext{
${ }^{20}$ Nesse sentido, Silva (2016, p. 203) afirma que o pretexto de respeito ao legislador é um argumento trivial, pois o que ocorre, em realidade, é que o tribunal "dá a sua interpretação ao dispositivo para compatibilizá-lo com aquilo que o próprio tribunal, e ninguém mais, acha que é constitucional. E essa é, no âmbito do controle de constitucionalidade, exatamente a tarefa do tribunal: interpretar um dispositivo questionado e verificar se ele é compatível com a interpretação que o mesmo tribunal faz da constituição".
} 
Outra categoria jurídica que deve ser referida, quando se fala de interpretação e aplicação das regras no âmbito da jurisdição constitucional, é a inconstitucionalidade parcial sem redução de texto, cuja hipótese de incidência é diversa daquela referida para a interpretação conforme a constituição ${ }^{21}$.

Na declaração de inconstitucionalidade parcial sem redução de texto não se questiona a constitucionalidade da lei ou da regra como um todo, nem se afastam alguns sentidos interpretativos da norma não condizentes com a Constituição. Trata-se de redução de parte da incidência da norma à luz dos eventos ou destinatários por ela abrangidos, de modo que, ao invés de uma técnica de interpretação, ela pode ser considerada o produto final de um julgamento abstrato de constitucionalidade.

O motivo de sua utilização é meramente redacional na medida em que "a eliminação de parte do dispositivo afetaria também a parte constitucional, surgindo uma lacuna sem justificativa substancial” (DIMOULIS; LUNARDI, 2014, p. 418).

Logo, enquanto a técnica de interpretação conforme a constituição atua no domínio da interpretação da lei, a nulidade sem redução (ou modificação) de texto "localiza-se no âmbito da aplicação, pois pretende excluir alguns casos específicos da aplicação da lei” (SILVA, 2006, p. 201), ou, em outros termos, considera-se inconstitucional "apenas determinada hipótese de aplicação da lei, sem proceder à alteração do seu programa normativo" (MENDES, 2010, p. $1.425)$.

No âmbito da jurisprudência e da doutrina alemã, que é a fonte da interpretação conforme, diferencia-se esta da declaração de nulidade parcial do texto nos moldes acima. Entretanto, é importante frisar que no direito alemão, como os juízes em geral não possuem competência para declarar a nulidade de uma lei (não há, portanto, controle difuso de constitucionalidade, mas apenas controle abstrato de constitucionalidade, de competência do Tribunal Constitucional), a eles não é lícito realizar a redução teleológica da lei a partir da técnica da nulidade parcial sem ou com redução do texto; por outro lado, não há óbice de que o magistrado alemão interprete conforme a constituição um regramento jurídico. Partindo disso,

\footnotetext{
${ }^{21}$ A atuação do Supremo Tribunal Federal sobre o tema também é objeto de críticas de Virgílio Afonso da Silva (2016, p. 200-201): "O Supremo Tribunal Federal, na maioria das vezes, refere-se a uma 'interpretação conforme a constituição sem redução de texto'. A redundância ou confusão é patente, pois parece claro que, se é mera interpretação (conforme a constituição), a redação do texto não pode ser modificada".
} 
Silva (2006, p. 201) controverte a possibilidade de o juiz brasileiro, no controle difuso de constitucionalidade, declarar a nulidade parcial de uma lei, afirmando que tal competência também no Brasil é exclusiva do Supremo Tribunal Federal; ao juiz seria possibilitado, no controle incidental, apenas afastar a aplicação da lei como um todo por inconstitucional. Em sentido oposto, Lunardi e Dimoulis (2014, p. 404) afirmam que são técnicas "que podem ser aplicadas em qualquer processo e instância em sistemas de controle de constitucionalidade difuso como o brasileiro". Por oportuno:

\begin{abstract}
Já no caso de inconstitucionalidade parcial sem redução de texto, o problema diz respeito aos casos reais em que a aplicação da norma deve ser permitida. Não se constata pluralidade de significados interpretativos, mas fiscalizam-se hipóteses de aplicação da norma, isto é, situações que, pela formulação da premissa maior, podem compor a premissa menor do silogismo jurídico. Na medida em que o dispositivo se aplica em algumas hipóteses, ocorre inconstitucionalidade. Nas demais hipóteses não há problema constitucional, sendo a inconstitucionalidade parcial. Em razão do imperativo da separação dos poderes, os Tribunais Constitucionais não podem excluir expressamente certas hipóteses de aplicação, pois se transformariam em legislador positivo, redigindo a norma em formulação diferente. Onde a norma diz ' $x$ ', o juiz não pode escrever ' $x-1$ '. Tampouco seria justificado declarar a inconstitucionalidade plena da norma, pois ela corretamente se aplica em algumas hipóteses (' $\mathrm{x}-1$ '). Assim sendo, só resta ao fiscal da constitucionalidade excluir de sua aplicação alguns casos, indicando isso em sua decisão, sem afetar a redação da norma (DIMOULIS; LUNARDI, 2014, p. 420).
\end{abstract}

Mendes (2010, p. 1427-1428) afirma que o STF, nas decisões proferidas nas ADIs 491 e 319 (todas relatadas por Moreira Alves), equipara a interpretação conforme a Constituição a uma declaração de inconstitucionalidade sem redução de texto ${ }^{22}$, gerando dificuldades de compreensão dessas técnicas, tanto que eventual conversão em uma técnica de decisão de inconstitucionalidade implicaria reduzir a sua incidência às decisões proferidas em controle abstrato, pois, do contrário, tais decisões, quando do controle concreto, deveriam ser objeto de reserva de plenário (o que não se exige na interpretação conforme propriamente dita). Além disso, ao fixar determinada interpretação como adequada constitucionalmente, não haveria possibilidade de declaração de todas as possíveis interpretações inconstitucionais. A partir de tais considerações, o autor conclui:

\begin{abstract}
Ainda que se não possa negar a semelhança dessas categorias e a proximidade do resultado prático de sua utilização, é certo que, enquanto na interpretação conforme à Constituição se tem, dogmaticamente, a declaração de que uma lei é constitucional com a interpretação que lhe é conferida pelo órgão judicial, constata-se, na declaração de nulidade sem redução de texto, a expressa exclusão, por inconstitucionalidade, de
\end{abstract}

\footnotetext{
${ }^{22}$ Dimitri Dimoulis e Soraya G. Lunardi (2014, p. 405) aduzem que o Supremo Tribunal Federal fez uma construção própria de tal técnica.
} 
determinadas hipóteses de aplicação do programa normativo sem que se produza alteração expressa do texto legal.

Assim, se se pretende realçar que determinada aplicação do texto normativo é inconstitucional, dispõe o Tribunal da declaração de inconstitucionalidade sem redução de texto, que, além de mostrar-se tecnicamente adequada para essas situações, tem a virtude de ser dotada de maior clareza e segurança jurídica, expressas na parte dispositiva da decisão (a lei X é inconstitucional se aplicável a tal hipótese; a lei Y é inconstitucional se autorizativa da cobrança do tributo em determinado exercício financeiro). (MENDES, 2010, p. 1.428).

Tal procedimento do Supremo Tribunal Federal também é criticado por Brust (2009, p. 509) ao aduzir que não é permitido equiparar tais categorias jurídicas, mormente porque a inconstitucionalidade parcial sem redução de texto "também dá origem a uma sentença manipulativa, no caso redutiva". E as implicações das denominadas sentenças manipulativas para o sistema jurídico são absolutamente diversas das produzidas pela técnica da interpretação conforme a Constituição, o que será objeto da análise a seguir.

\section{DECISÕES CONSTITUCIONAIS MANIPULATIVAS}

A ampliação da interpretação conforme a Constituição para além do objetivo de salvar o texto da declaração de inconstitucionalidade quando há alternâncias interpretativas expandiu sobremaneira o seu alcance no sentido de se permitir ao julgador "produzir sentenças que afetam o próprio conteúdo normativo complexo do preceito, reduzindo-o, aumentando-o e, até mesmo, substituindo-o" (BRUST, 2009, p. 508), ou seja, de proferir sentenças manipulativas ${ }^{23}$.

Nesses moldes, o objetivo de harmonizar as normas jurídicas infraconstitucionais com a Constituição dá origem às sentenças interpretativas em sentido amplo, as quais se dividem em decisões (a) interpretativas em sentido estrito e (b) manipulativas ou modificativas, cuja diferença é bem assinalada pela doutrina da seguinte forma:

De todos os modos, uma coisa é certa: com a interpretação conforme a Constituição tomada em seu sentido estrito ou originário, o Tribunal não adiciona sentido ao texto legal. Limita-se a escolher as opções constitucionais entre as interpretações alternativas emergentes do texto legal, dando origem à sentença interpretativa de

\footnotetext{
23 “Costuma-se dizer que as sentenças manipulativas são aquelas decisões interpretativas de procedência que declaram inconstitucional uma parte do conteúdo normativo derivado conjuntamente ou contemporaneamente do texto, conservando-o íntegro" (BRUST, 2014, p. 160-161).
} 
improcedência (no Brasil, de constitucionalidade). Quando o Tribunal, com base na Constituição, adiciona sentido ao texto legal (ou o reduz ou substitui) está em realidade ditando uma sentença manipulativa. Essa interpretação também parte da interpretação conforme (lato sensu), mas vai além, porque modifica o próprio conteúdo normativo complexo do preceito. E isso pode se refletir, eventualmente, numa indevida invasão da competência de outro órgão de soberania, mas especificamente, do Poder Legislativo (BRUST, 2009, p. 512).

Assim sendo, a sentença interpretativa em sentido estrito é aquela em que se aplica a técnica da interpretação conforme (quando o tribunal define, dentre as interpretações possíveis que emergem do texto legal, aquela mais adequada à Constituição), enquanto a sentença manipulativa (terminologia utilizada na Itália) ou modificativa (terminologia utilizada em Portugal) se subdivide em três espécies: redutora, aditiva e substitutiva ${ }^{24}$.

A sentença manipulativa aditiva, ou com efeito acumulativo, provoca o alargamento do âmbito normativo de uma regra, com o juízo simultâneo (ora combatido) de inconstitucionalidade da parte omissa ou deficiente onde se deixa de regular as consequências ou medidas tidas como adequadas, quando contempla uma exceção ou quando impõe uma condição complementar a certas situações jurídicas, enquanto a sentença manipulativa substitutiva, ou com efeito substitutivo, reconhece a inconstitucionalidade quando implica a substituição de uma disciplina jurídica contida na regra ou quando reconhece a inconstitucionalidade de uma prescrição, substituindo-a por outra (CANOTILHO, 2003, p. $1.019)^{2526}$.

Acrescente-se que a decisão aditiva ${ }^{27}$ tem como fundamento atender concretamente ao princípio da igualdade, pois procura equiparar situações jurídicas análogas àquelas previstas originalmente na norma e que não foram contempladas pelo seu âmbito de aplicação, podendose afirmar que o Tribunal, para não ter de reconhecer a inconstitucionalidade por afronta ao

\footnotetext{
${ }^{24}$ Leo Brust (2014) ao tratar das sentenças manipulativas no capítulo 04 de sua obra (p. 145-310), adaptando a classificação ao sistema jurídico nacional, as divide em (a) sentença de inconstitucionalidade parcial sem redução de texto (parcial qualitativa), (b) sentença aditiva e (c) sentença substitutiva.

${ }^{25}$ Canotilho ainda esclarece que tais categorias são "originárias da doutrina e jurisprudência italianas, que sugestivamente, utilizam o conceito geral de sentenças manipulativas (decisioni manipolative) para designar as técnicas de decisão transformadoras dos significados da lei” (CANOTILHO, 2003, p. 1.019).

${ }^{26}$ Outra diferenciação afirma que a decisão manipulativa de efeitos aditivos "verifica-se quando a corte constitucional declara inconstitucional certo dispositivo legal não pelo que expressa, mas pelo que omite, alargando o texto da lei ou seu âmbito de incidência. As manipulativas com efeitos substitutivos, por sua vez, são aquelas em que o juízo constitucional declara a inconstitucionalidade da parte em que a lei estabelece determinada disciplina ao invés de outra, substituindo a disciplina advinda do poder legislativo por outra, consentânea com o parâmetro constitucional" (MENDES, 2010, 9. 1432-1433).

${ }^{27}$ Para quem quiser aprofundar o estudo do tema, a doutrina exemplifica como decisões aditivas as decisões proferidas pelo STF na ADI 939 e na ADI 2.979.
} 
dever de isonomia, acaba por condicionar a manutenção da norma no sistema jurídico desde que ela seja interpretada ampliativamente, abarcando situações ou destinatários não previstos (BRUST, 2014, p. 174) ${ }^{28}$.

Ademais, a sentença substitutiva, considerada a mais polêmica e rara dentre as modalidades descritas, caracteriza-se pela substituição de parte do conteúdo normativo por outro diverso, sem - é importante frisar esse aspecto - alterar o seu texto, ou seja, provoca-se um intercâmbio de um parâmetro fático ou jurídico por outro ${ }^{29}$.

A sentença manipulativa redutora corresponde, por sua vez, ao que no Brasil é aceito sem maiores ressalvas pela doutrina, especialmente a partir do advento da Lei 9.868/99 ${ }^{30}$, como inconstitucionalidade parcial sem redução de texto, ou seja, decisões cujo resultado aponta para a redução do âmbito de aplicação da norma ou para a "exclusão de uma determinada aplicação do conteúdo normativo" (BRUST, 2014, p. 166).

As necessidades, ou os fundamentos que justificam tal avanço da jurisdição constitucional no Brasil, Espanha, Portugal e Itália, podem ser assim sintetizados:

(...) em lição perfeitamente adequada ao direito pátrio, Augusto Martín de La Vega ressaltou ser possível compreender a proliferação das decisões manipulativas de efeitos aditivos, levando-se em conta três fatores: a) a existência de uma Carta política de perfil marcadamente programático e destinada a progressivo desenvolvimento; b) a permanência de um ordenamento jurídico-positivo com marcados resquícios autoritários; e c) a ineficácia do Legislativo para responder, em tempo adequado, às

\footnotetext{
${ }^{28}$ Jorge Miranda (2003, p. 68), por sua vez, refere que nas decisões aditivas "a inconstitucionalidade detectada não reside tanto naquilo que a norma preceitua quanto naquilo que ela não preceitua. Ou, por outras palavras, a inconstitucionalidade acha-se na norma na medida em que não contém tudo aquilo que deveria conter para responder aos imperativos da Constituição. E então, o órgão de fiscalização acrescenta (e, acrescentando, modifica) esse elemento que falta"

${ }^{29}$ Um caso concreto ilustra adequadamente o quão problemática é a sua admissão: “A natureza 'paralegislativa' da sentença substitutiva pode ser observada, por exemplo, numa sentença da Corte Constituzionale em que declarou a inconstitucionalidade de determinado preceito legal na parte em que estabelecia certa pena mínima em dois anos no lugar de seis meses e máxima de quatro anos no lugar de dois anos. É claro que este exemplo é extremo, tanto que marcou um dos casos de rebelião do Poder Judiciário italiano, posto que os juízes militares se limitaram a aceitar a parte ablativa do veredicto, reivindicando como sua a tarefa interpretativa de integrar a lacuna" (BRUST, 2014, p. 178).

${ }^{30}$ A importância do parágrafo único do artigo 28 da Lei n. 9868/99 para o sistema jurídico nacional é bem explicitada por Lenio Luiz Streck (2002, p. 444): “(...) com a institucionalização da interpretação conforme a Constituição e da inconstitucionalidade parcial sem redução de texto através da Lei 9.868, o Poder Legislativo brasileiro admite (explicitamente) que o Poder Judiciário possa exercer uma atividade de adaptação e adição/adjudicação de sentido aos textos legislativos, reconhecendo, ademais, que a função do Poder Judiciário, no plano do controle de constitucionalidade, não mais se reduz - repita-se - à clássica concepção de 'legislador negativo'. À evidência, isso não significa dizer que o Judiciário se transformará em legislador positivo. O instituto da interpretação conforme e os demais mecanismos hermenêuticos não têm o condão de transformar o Poder Judiciário em um órgão que está acima da Constituição".
} 
exigências de atuação da Constituição e à conformação do ordenamento preexistente ao novo regime constitucional (MENDES, 2010, p. 1433).

A viabilidade jurídica de os Tribunais proferirem sentenças manipulativas gera inúmeras controvérsias no âmbito dos limites da jurisdição constitucional, sobretudo quando se considera que se trata de uma atuação positiva do Tribunal, que, ao assim agir, concorreria com o Parlamento na atividade legislativa ${ }^{31}$.

Foi exatamente isso que ocorreu no caso do julgamento envolvendo o aborto de fetos anencéfalos, cuja existência também é considerada um típico caso de derrotabilidade na concepção da capacidade de as regras jurídicas acomodarem exceções implícitas e que pressupõe a legitimidade de o Judiciário as reconhecer, desde que observadas determinadas exigências argumentativas ${ }^{32}$.

\section{O CASO DO ABORTO DE FETO ANENCÉFALO - ADPF 54}

Na decisão proferida na Arguição de Descumprimento de Preceito Fundamental ADPF $54^{33}$, julgada em 12/04/2012 - o Supremo Tribunal Federal, por maioria de seus Ministros, julgou, nos termos do pedido formulado, "inconstitucional interpretação de a

\footnotetext{
${ }^{31}$ Conforme Lenio Streck (2002, p. 471-473), há muito os tribunais, em especial o STF, fazem uso de decisões manipulativas, ou proferem decisões eminentemente contra ou extra legem, as quais não são contestadas ou polemizadas porque fazem parte do processo de atribuição de sentido ao direito, que é inerente ao processo hermenêutico; apenas são contestadas, sob o argumento do legislador positivo, quando causam perplexidade pela desconformidade com aquilo preestabelecido pela dogmática ou quando se trata de hipóteses jurídicas extremamente controvertidas.

${ }^{32}$ Sobre as rigorosas exigências argumentativas para que o Judiciário não aplique uma regra jurídica válida, indicase GAVIÃO FILHO; MUNHOZ DE ANDRADE, 2015; para um exame das condições que legitimam uma decisão contra legem, aconselha-se BUSTAMANTE, 2010; sobre as condições de superabilidade de uma regra jurídica, ver ÁVILA, 2015.

${ }^{33}$ Uma descrição detalhada dos fundamentos de cada Ministro, com uma interessante abordagem dos métodos (subsunção e ponderação) e modelos (coerentistas e inferencial) decisórios aplicados ao acórdão, é realizada por Juliana Sípoli Col (2012). Nesse mesmo domínio, Maranhão apresenta uma importante e complexa análise sobre os princípios e as regras jurídicas (implícitas e explícitas) envolvidos no caso ao longo de sua obra (2012) sob a ótica de uma proposta coerentista inferencial embasada no inclusivismo lógico como concepção do Direito.
} 
interrupção da gravidez de feto anencéfalo ser conduta tipificada nos artigos 124, 126 e 128, incisos I e II, do Código Penal” ${ }^{34}$.

Os termos da ementa evidenciam que foi aplicada a técnica da interpretação conforme a Constituição, conquanto inexistente a pluralidade de interpretações que decorressem dos termos estritos da legislação, senão a partir de entendimentos jurisprudenciais e construções doutrinárias em benefício da tese favorável à atipicidade da conduta. Os votos vencedores, em sua grande maioria, ratificaram o seguinte caminho argumentativo: se o anencéfalo não é dotado de vida (ou de possibilidade de vida fora do útero ou de vida digna tutelada pelo Direito), logo não haverá crime no comportamento tendente à interrupção voluntária da gravidez (ausente, portanto, subsunção do fato à norma).

O Min. Ricardo Levandowski, que no mérito foi contrário ao pedido (pois para ele o Tribunal estaria atuando como legislador positivo), questionou a utilização da interpretação conforme, pois o limite dessa técnica não permitiria afrontar a literal expressão da lei ("quando a lei é clara não há espaço para interpretação"), contrariando-se a vontade do legislador e, desse modo, não se poderia substituir o critério estabelecido democraticamente (via legislatura) pela decisão do órgão julgador. Em suas palavras, há "duas barreiras intransponíveis, quais sejam: de um lado, não é dado ao hermeneuta afrontar a expressão literal da lei; de outro, não pode ele contrariar a vontade manifesta do legislador e, muito menos, substituir-se a ele".

Por sua vez, o Min. Gilmar Ferreira Mendes, que julgou procedente o pedido - sob o argumento do reconhecimento de uma terceira excludente de ilicitude (ainda não explicitada no Código Penal), que se legitima pelas orientações interpretativas decorrentes das exceções formuladas pelo legislador -, enfatizou que não se trata de interpretação conforme, mas sim de decisão manipulativa com eficácia aditiva. Pertinente, então, transcrever parte dos fundamentos do correspondente voto ${ }^{35}$ :

Ao rejeitar a questão de ordem levantada pelo Procurador-Geral da República, o Tribunal admitiu a possibilidade de, ao julgar o mérito da ADPF 54, atuar como verdadeiro legislador positivo, acrescentando mais uma excludente de ilicitude - no

\footnotetext{
${ }^{34}$ BRASIL. Supremo Tribunal Federal. ADPF 54, Relator: Min. Marco Aurélio, Tribunal Pleno, julgado em 12/04/2012, Acórdão Eletrônico DJe-080, divulgado em 29/04/2013, publicado em 30/04/2013, RTJ vol-0022601, pp.00011.

${ }^{35}$ No voto do Min. Gilmar Ferreira Mendes também ocorrem referências à doutrina portuguesa e exemplos de decisões manipulativas da Corte Constitucional italiana.
} 
caso de o feto padecer de anencefalia - ao crime de aborto. Isso quer dizer que, pelo menos segundo o meu voto, está rechaçado o argumento da autora, de atipicidade do fato.

Acolho a hipótese de que a Corte criará, ao lado das já existentes (art. 128, I e II), uma nova hipótese de excludente de ilicitude do aborto.

Portanto, não se pode negar que o Supremo Tribunal Federal está a se livrar do vetusto dogma do legislador negativo e, nesse passo, alia-se à mais progressiva linha jurisprudencial das decisões interpretativas com eficácia aditiva, já adotadas pelas principais Cortes Constitucionais europeias. A assunção de uma atuação criativa pelo Tribunal poderá ser determinante para a solução de antigos problemas relacionados à inconstitucionalidade por omissão, que muitas vezes causa entraves para a efetivação de direitos e garantias fundamentais assegurados pelo texto constitucional.

Em verdade, é preciso deixar claro que a prolação de decisões interpretativas com efeitos aditivos não é algo novo na jurisprudência do STF. Poder-se-ia, inclusive, atestar que se trata apenas de uma nova nomenclatura, um novo (e mais adequado) termo técnico para representar formas de decisão que o Tribunal costuma tomar quando realiza a conhecida interpretação conforme a Constituição e, com isso, acaba por alterar, ainda que minimamente, os sentidos normativos do texto legal. [...].

[...]. Portanto, ainda que se queira denominar a decisão tomada nesta ADPF como interpretação conforme, ela não deixará de ser, consoante a nomenclatura tecnicamente mais adequada, uma decisão interpretativa (manipulativa) com efeitos aditivos.

É certo que a incidência de decisões com efeitos aditivos em matéria criminal não está livre de críticas. Parece sensato assumir todas as cautelas quando se trata de produzir decisões manipulativas sobre normas de caráter penal, tendo em vista os princípios da legalidade (e reserva de lei e reserva de Parlamento) e da tipicidade (cerrada) penal. A sentença aditiva in malam partem é extremamente reprovável, todavia, se proferida in bonam partem, abre-se uma brecha explorável para a prolação de decisão manipulativa que tenha efeito restritivo da norma penal, não ofensiva ao postulado da reserva de lei. [...].

Portanto, tal como vivenciado na realidade italiana, não seria incorreto considerar a possibilidade de que, também entre nós, o Supremo Tribunal Federal, ante a premente necessidade de atualização do conteúdo normativo do art. 128 do Código Penal de 1940, venha a prolatar uma decisão com efeitos aditivos para admitir que, além do aborto necessário (quando não há outro meio de salvar a vida da gestante) e do aborto no caso de gravidez resultante de estupro, não se deve punir o aborto praticado por médico, com o consentimento da gestante, se o feto padece de anencefalia.

Essa parece ser uma técnica viável de decisão, que de nenhuma maneira atenta contra os princípios da legalidade (e reserva de lei) estrita e da tipicidade penal. Faço, no entanto, uma imprescindível ressalva: é que as decisões manipulativas de efeitos aditivos, como essa que se propõe, devem observar limites funcionais claros, isto é, elas devem submeter-se à liberdade de conformação do legislador, que poderá, a qualquer tempo, editar norma sobre o tema. Desse modo, é preciso reconhecer que a decisão desta Corte não impedirá o advento de legislação sobre o assunto, devendo antes servir de estímulo à atuação do legislador ${ }^{36}$.

\footnotetext{
${ }^{36}$ Oportuno registrar que, em sede doutrinária, Mendes (2010, p. 1.432) já destacava que em caso de procedência no julgamento do caso do aborto do feto anencéfalo (ADPF 54), o Supremo Tribunal Federal, "dando interpretação conforme aos arts. 124 a 128 do Código Penal, invariavelmente proferirá uma típica decisão manipulativa com eficácia aditiva", de modo a se "livrar do vetusto dogma do legislador negativo e aliar-se-á a mais progressiva linha jurisprudencial das decisões interpretativas com eficácia aditiva, já adotada pelas principais Cortes Constitucionais do mundo".
} 
Com efeito, evidencia-se claramente que é inadequado tratar o caso em comento, paradigmático nos seus mais importantes aspectos argumentativos, como exemplo de interpretação conforme, pois a legislação infraconstitucional sobre o aborto é clara e taxativa ${ }^{37}$, inexistindo, portanto, dúvidas interpretativas oriundas do seu conteúdo semântico e que imporiam o salvamento da lei, justificativa que afasta, pois, a aplicação de tal técnica de decisão ${ }^{38}$.

Por outro lado, ao contrário do exposto no voto de Mendes, não se trata de uma decisão manipulativa com eficácia aditiva (agregando conteúdo normativo à regra), senão de uma decisão com eficácia redutiva ${ }^{39}$ (pela subtração de aplicação da regra que veda o aborto), embora com a formulação de uma nova exceção que se inclui àquelas excludentes previstas pelo direito positivo legislado.

Note-se que tal decisão manipulativa redutiva corresponderia, assim, à hipótese de inconstitucionalidade parcial sem modificação de texto ${ }^{40}$, ao excluir alguns casos específicos do âmbito de aplicação da lei, com a ressalva de que referido expediente não decorreria de qualquer dificuldade semântica derivada da compreensão mais ou menos inequívoca das palavras utilizadas pelo legislador; trata-se, em realidade, de redução teleológica do escopo normativo da regra, como aduz Larenz (1997, p. 556):

A redução teleológica comporta-se em relação à interpretação restritiva de modo semelhante à analogia particular em relação à interpretação extensiva. O âmbito de aplicação da norma umas vezes reduz-se mais do que indica o limite que se infere do

\footnotetext{
${ }^{37} \mathrm{O}$ art. 124 do Código Penal dispõe que é crime "provocar aborto em si mesma ou consentir que outrem lhe provoque", ou seja, não há dúvida acerca do significado do ato de abortar que imponha discussão jurídica interpretativa acerca de sua extensão para fins de tipicidade. Do mesmo modo, as exceções constantes do texto legal (art. 132) não acarretam pluralismo de interpretações, pois não se pune o aborto praticado por médico "se não há outro meio de salvar a vida da gestante" e "se a gravidez resulta de estupro e o aborto é precedido de consentimento da gestante ou, quando incapaz, de seu representante legal".

38 Nesse mesmo sentido Dimoulis e Lunardi (2014, p. 414) criticam a aplicação da técnica de interpretação conforme na decisão proferida na ADIn 4.277 (caso da união homoafetiva), pois ali houve afronta aos seus dois limites, textual e volitivo (afronta à clara vontade do legislador).

${ }^{39}$ É precisa a diferenciação entre sentenças redutoras e aditivas fornecida por Jorge Miranda (2003, p. 68): "Nas decisões redutivas ou de inconstitucionalidade parcial há um segmento da norma que cai para ela ser salva. Nas decisões aditivas há um segmento ou uma norma que se acrescenta com idêntico fim. E nisto, por seu turno, se denota algo de comum às decisões limitativas e, dalguma sorte mesmo às decisões interpretativas: todas elas pressupõem um sistema de fiscalização que, longe de se fechar sobre si, aparece inserido no contexto global de Constituição e que, portanto, reconhece aos respectivos órgãos um papel ativo na realização dos princípios constitucionais".

${ }^{40}$ Leo Brust $(2009$, p. 509) também faz críticas a esse procedimento de equiparação do STF, "pois quando este afirma que a interpretação conforme a Constituição, tomada em seu aspecto negativo, não mais é que é uma inconstitucionalidade parcial sem redução de texto, também dá origem a uma sentença manipulativa, no caso redutiva".
} 
sentido literal possível e outras vezes amplia-se. Em ambos os casos, trata-se de uma continuidade de interpretação transcendendo o limite do sentido literal possível. Como este limite é 'fluido', pode ser duvidoso, no caso particular, se se trata ainda de uma interpretação restritiva ou já de uma redução teleológica. A jurisprudência fala, não raras vezes, de interpretação restritiva - certamente a fim de dar, desse modo, a impressão de maior 'fidelidade à lei' -, quando na realidade já não se trata de interpretação, mas de uma redução teleológica. Mas se a redução está estritamente dirigida à própria teleologia da lei e se se têm em conta as barreiras nela estabelecidas, que ainda havemos de mencionar, então não é menos 'fiel à lei' do que qualquer interpretação teleológica.

Prosseguindo, essa redução teleológica, embora seja muitas vezes criticada e outras vezes aplaudida, nada mais assinala do que uma hipótese de adequação de uma regra geral a um caso específico cujo resultado, se não houver a intervenção judicial, pode ser manifestamente injusto, tal como visto no tópico referente à derrotabilidade.

Nesse aspecto, os fundamentos do Min. Gilmar Mendes aproximam o seu voto do fenômeno da derrotabilidade das regras jurídicas em consonância com a concepção adotada pelo presente ensaio, ou seja, pela característica de inserção de uma cláusula de exceção a uma regra geral em decorrência da excepcionalidade do caso particular, pois há menção expressa do reconhecimento de uma nova hipótese de exclusão de ilicitude ou, dito de outro modo, da aceitação de uma inédita exceção à regra geral abstrata que criminaliza a prática abortiva.

Então, sob o ângulo da defeasibility, o resultado do julgamento foi o de reconhecer uma exceção implícita à regra jurídica geral de ser proibido o aborto ao não se aplicar a consequência jurídica disposta na lei, ainda que a hipótese fática se enquadre perfeitamente na descrição hipotética abstrata da proposição jurídica. Assim, no sistema jurídico brasileiro atual é vedada a interrupção da gravidez, a menos que (a) para salvar a vida da gestante, (b) em caso de estupro e (c) na hipótese de o feto padecer comprovadamente da anencefalia.

As vantagens do reconhecimento do fenômeno da derrotabilidade, especialmente sob a atuação da decisão manipulativa com efeito redutivo (ou mesmo da inconstitucionalidade parcial sem redução de texto) no controle de constitucionalidade, são explicadas pelo argumento de que tanto o raciocínio jurídico como o comando da decisão são apresentados de modo absolutamente claro e sem eufemismos, em flagrante compatibilização com o princípio da segurança jurídica (previsibilidade e estabilidade do Direito, com orientação precisa das expectativas sociais ${ }^{41}$ ), quer dizer, com o oferecimento explícito de critérios argumentativos

\footnotetext{
${ }^{41}$ Humberto Ávila (2014, p. 282) define segurança jurídica como "uma norma-princípio que exige, dos Poderes Legislativo, Executivo e Judiciário, a adoção de comportamentos que contribuam mais para a existência, em
} 
justificadores das premissas fáticas e jurídicas que amparam a conclusão da necessidade, naquela hipótese excepcional, de superação de uma regra pelo Poder Judiciário a partir da introdução de uma exceção e, destarte, da criação de uma nova regra geral que deve ser respeitada pela comunidade jurídica em geral.

Essa aplicação distorcida da interpretação conforme a Constituição realizada pelo Supremo Tribunal Federal, decorrente do dogma do legislador negativo, é bastante grave, devendo ser questionada ${ }^{42}$, pois pretende mascarar a realidade pela simplificação indevida da problemática que envolve a jurisdição constitucional, sobretudo quando se destacam excessivamente princípios jurídicos sem diferenciá-los adequadamente de valores morais ${ }^{43}$, conforme há muito apontado pela doutrina ${ }^{44}$.

Ao continuar a lançar mão a técnica da interpretação conforme a Constituição para aparentar maior fidelidade à lei, como refere Larenz (2007, p 556), ou como um guarda-chuva, na feliz expressão de Brust (2014, p. 155), o Supremo Tribunal Federal realmente perdeu uma oportunidade histórica de demonstrar à sociedade como ocorre o desenvolvimento do Direito via Poder Judiciário, ainda que isso implique evidenciar também os riscos hermenêuticos inerentes envolvidos na prática interpretativa da jurisdição constitucional.

\footnotetext{
benefício dos cidadãos e na sua perspectiva, de um estado de confiabilidade e de calculabilidade jurídica, com base na sua cognoscibilidade, por meio da controlabilidade jurídico-racional das estruturas argumentativas reconstrutivas de normas gerais e individuais, como instrumento garantidor do respeito à sua capacidade de - sem engano, frustração, surpresa e arbitrariedade - plasmar digna e responsavelmente o seu presente e fazer um planejamento estratégico juridicamente informado do seu futuro".

${ }^{42}$ Não é diversa a manifestação de Brust (2009, p. 523).

${ }^{43}$ Sobre a tirania dos valores, Eros Roberto Grau (2016, p. 123) é preciso: “A submissão de todos nós a essa tirania é tanto mais grave quando se perceba a promiscuidade dos valores que, por força de ponderações que os revalorizam, ocorre no plano da aplicação do direito. Refiro-me, reiteradamente, às ponderações entre princípios que os juristas - em especial os juízes - operam visando a impor os seus valores, no exercício de pura discricionariedade, em regra não se dando conta de que o fazem".

44 “Ao deixar-se conduzir pela ideia da realização de valores materiais, dados preliminarmente no direito constitucional, o tribunal constitucional transforma-se numa instância autoritária. No caso de uma colisão, todas as razões podem assumir o caráter de argumentos de colocação de objetivos, o que faz ruir a viga mestra introduzida no discurso jurídico pela compreensão deontológica de normas e princípios do direito. (...). Normas e princípios possuem uma força de justificação maior do que a de valores, uma vez que podem pretender, além de uma especial dignidade de preferência, uma obrigatoriedade geral, devido ao seu sentido deontológico de validade; valores têm que ser inseridos, caso a caso, numa ordem transitiva de valores. E, uma vez que não há medidas racionais para isso, a avaliação realiza-se de modo arbitrário ou irrefletido, seguindo ordens de precedência e padrões consuetudinários" (HABERMAS, 2007, p. 321).
} 


\section{CONSIDERAÇÕES FINAIS}

O caso do aborto do feto anencéfalo exemplifica de maneira privilegiada a problemática que envolve a interpretação conforme a Constituição e a sua utilização distorcida pelo Supremo Tribunal Federal, na medida em que o caso em comento recorre a tal técnica sem maiores esclarecimentos, além de ignorar os condicionamentos teóricos dispensados pela doutrina especializada, como o requisito da existência de duas ou mais interpretações possíveis decorrente das palavras utilizadas no texto legal passível de interpretação pelo aplicador do Direito.

Tal atuação gera confusões conceituais e metodológicas, cuja explicação principal é a de que os membros do Tribunal, em sua grande maioria, não pretendem enfrentar abertamente o dogma do legislador negativo e, assim, as dificuldades que decorrem inevitavelmente da jurisdição constitucional e do próprio desenvolvimento (e criação) do Direito mediante decisões judiciais, conforme já demonstrara Hart em meados do século passado.

Por outro lado, a situação paradigmática escolhida ilustra perfeitamente uma hipótese do fenômeno da derrrotabilidade das regras jurídicas, na medida em que se reconheceu judicialmente uma exceção implícita à regra jurídica geral de ser proibido (e criminalizado) o aborto, a qual se junta às outras duas exceções expressas constantes da lei penal, no sentido de se autorizar o aborto quando não há outro meio de salvar a vida da gestante e em caso de gravidez resultante de estupro.

Do mesmo modo, a decisão demonstra que, no âmbito da jurisdição constitucional, a redução teleológica de uma regra, com a criação de uma exceção, encontra amparo na técnica da inconstitucionalidade parcial sem redução de texto, que se amolda também a uma sentença manipulativa redutora.

O fato de a decisão ter sido proferida em controle concentrado gera repercussões ainda maiores ao sistema jurídico nacional, ante o seu efeito vinculante e sua eficácia erga omnes, maximizando a importância de se estudar o fenômeno da derrotabilidade das regras jurídicas e, assim, a problemática das exceções implícitas no Direito. 


\section{REFERÊNCIAS BIBLIOGRÁFICAS}

ATRIA, Fernando. On Law and Legal Reasoning. Hart Publishing, Oxford and Portland, Oregon, 2002.

ÁVILA, Humberto. Teoria da segurança jurídica. 3. ed. - São Paulo, SP: Malheiros Editores, 2014.

. Teoria dos Princípios: da definição à aplicação dos princípios jurídicos. $16^{\mathrm{a}}$ edição, rev. e atual. São Paulo: Malheiros Editores Ltda, 2015.

BELTRÁN, Jordi F. e RATTI, Giovanni B. Legal Defeasibility: An Introduction. The Logic of Legal Requirements: Essays on Defeasibility. Great Britain: Oxford University Pres, 2012, p. 01-07.

BÄCKER, Carsten. Regras, princípios e derrotabilidade. Revista Brasileira de Estudos Políticos, Belo Horizonte, n. 102, p. 55-82, jan./jun. 2011.

BIX, Brian. Defeasibility and Open Texture. The Logic of Legal Requirements: Essays on Defeasibility. Great Britain: Oxford, Oxford University Pres, 2012, p. 193-201.

BRUST, Leo. A interpretação conforme a Constituição e as sentenças manipulativas. Revista Direito GV, São Paulo, n. 10, p. 507-526, jul. /dez. 2009.

Juruá, 2014.

Controle de constitucionalidade: a tipologia das decisões do STF. Curitiba:

BUSTAMANTE, Thomas. Princípios, regras e conflitos normativos: uma nota sobre a superabilidade das regras jurídicas e as decisões contra legem. Revista Direito, Estado e Sociedade, n. 37, jul/dez 2010, p. 152-180.

ANOTILHO, Joaquim José Gomes. Direito constitucional e teoria da constituição. 7 ed., 18 reimp. Coimbra: Almedina 2003.

CLÈVE, Clèmerson Merlin; LORENZETTO, Bruno Meneses. Constituição, governo democrático e níveis de intensidade do controle jurisdicional. Revista Judiciária do Paraná, Curitiba , v.10, n.10, p. 17-73, nov. 2015.

COL, Juliana Sípoli. Coerência, ponderação de princípios e vinculação à lei: métodos e modelos. Orientador Juliano Souza de Albuquerque Maranhão. São Paulo: USP, 2012. Dissertação de mestrado.

DUARTE D'ALMEIDA, Luís. Allowing for exceptions: A Theory of Defences and Defeasibility in Law. Oxford Legal Philosophy. Oxford: Oxford University Press, 2015.

GAVIÃO FILHO, Anizio Pires; MUNHOZ DE ANDRADE, Rosemeri. Superabilidade das Regras Jurídicas. Processo, hermenêutica e efetividade dos direitos I [e-book] / organizadores Alexandre Freire Pimentel, Fábio Túlio Barroso, Lúcio Grassi Gouveia. - Recife: APPODI, 2015. 
GRAEFF, Patrícia: Derrotabilidade, Vagueza e Textura Aberta: Um estudo acerca dos limites do Direito segundo Herbert Hart, Orientador: Paulo Baptista Caruso MacDonald. Coorientador: Alfredo Carlos Storck. Dissertação (Mestrado) - Universidade Federal do Rio Grande do Sul, Instituto de Filosofia e Ciências Humanas, Programa de Pós-Graduação em Filosofia, Porto Alegre, 2015.

HABERMAS, Jürgen, 1929. Direito e democracia: entre facticidade e validade, volume I / Jürgen Habermas; tradução: Flávio Beno Siebeneichler. Rio de Janeiro: Tempo Brasileiro, 1997.

HART, H. L. A. The ascription of responsability and rights. Proceedings of the Aristotelian Society, n. 49, 1948-1949, p. 171-194.

O conceito de Direito. 3 ed, tradução de A. Ribeiro Mendes. Lisboa: Fundação Calouste Gulbenkian, 2001.

GRAU, Eros Roberto. $O$ direito posto e o direito pressuposto. $9^{\mathrm{a}}$ edição, revista e ampliada. - São Paulo: Malheiros, 2014.

Por que tenho medo de juízes: (a interpretação/aplicação do direito e os princípios). - 7. ed. refundida do Ensaio e discurso sobre a interpretação / aplicação do direito. - São Paulo: Malheiros, 2016.

LARENZ, Karl. Metodologia da ciência do direito. 3 ed. Lisboa: Fundação Calouste Gulbenkian 1997.

LUNARDI, Soraya Regina Gasparetto; DIMOULIS, Dimitri. Interpretação conforme a Constituição e declaração de inscontitucionaldiade sem redução de texto. Problemas da aplicação judicial do direito constitucional. Revista Brasileira de Estudos Constitucionais : RBEC, Belo Horizonte, v.8, n.29, p. 403-425, maio/ago. 2014.

MACCORMICK, Neil. H. L. A. Hart; tradução Cláudia Santana Martins; revisão técnica Carla Henriete Beviláqua. - Rio de Janeiro: Elsevier, 2010.

MARANHÃO, Juliano Souza de Albuquerque. Positivismo jurídico lógico-inclusivo. São Paulo, Marcial Pons, 2012. (Coleção filosofia e direito).

MENDES, Gilmar Ferreira. Curso de direito constitucional / Gilmar Ferreira Mendes, Inocêncio Mártires Coelho, Paulo Gustavo Gonet Branco. - 5. ed. ver. e atual. - São Paulo: Saraiva, 2010.

MIRANDA, Jorge. Controle da Constitucionalidade e Direitos Fundamentais. Revista da EMERJ, v. 06, n. 21, 2003, p. 61-84.

PINO, Giorgio. Neil MacCormick on Interpretation, Defeasibility, and the Rule of Law. Paper presented at the Conference Legal Reasoning and European Laws: the Perspective of Neil MacCormick (European University Institute, Florence, 21 May 2010). 
RODRIGUEZ, Jorge L.; SUCAR, Germán. Las trampas de la derrotabilidad: niveles de análisis de la indeterminación del derecho. Relevancia normativa em la justificación de las decisiones judiciales. El debate Bayón-Rodriguez sobre la derrotabilidad de las normas jurídicas. Bogotá: Universidade Externado de Colombia, 2003, p. 103-155.

SARMENTO, Daniel; SOUZA NETO, Cláudio Pereira de. Notas sobre Jurisdição Constitucional e Democracia: a questão da "última palavra" e alguns parâmetros de autocontenção judicial. Revista Quaestio Iuris, vol.06 (2013), nº2. p. 119-161.

SILVA, Virgílio Afonso da. Interpretação conforme a Constituição: entre a trivialidade e a centralização judicial. Revista Direito GV, São Paulo, v. 2, n. 1, p. 191-210, jan/jun. 2006.

STRECK, Lenio Luiz. Jurisdição constitucional e hermenêutica: uma nova crítica do Direito. Porto Alegre: Livraria do Advogado, 2002.

VASCONCELLOS, Fernando Andreoni. Hermenêutica jurídica e derrotabilidade. Curitiba: Juruá, 2010.

Data de Submissão: 08/04/2020

Data de Aceite: 09/05/2020 